\title{
Long Term Effect of Morning Walk on Selected Health Indicators in Bengali Men
}

\author{
Dr. Sandip Sankar Ghosh*
}

Assistant Professor, Department of Physical Education, University of Kalyani, Kalyani, Nadia West Bengal, India

DOI: $10.36348 /$ jaspe.2020.v03i08.005 $\quad$ | Received: 30.07 .2020 | Accepted: 06.08.2020 | Published: 09.08 .2020

*Corresponding author: Dr. Sandip Sankar Ghosh

Abstract

Background: The researcher motivated a group of Govt. servant to start morning walk for the benefit of their health \& fitness. At the very outset researcher discuss and assured them to monitor the training program targeted for the improvement of their health \& fitness status and at the same time he thought to conduct a research work on them. Objective: The objective of this research work was to find out the effectiveness of morning walk on WHR, BMI, BP and RHR in Bengali men under the age of 40 years. Methods: Total thirty $(\mathrm{N}=30)$ male Govt. servant, few office workers $\&$ few school teachers, were considered as subject for the present study. They were purposefully divided into two equal groups - One group was treated as experimental group $(n=15)$ another group was treated as control group $(n=15)$. The age of the subjects were ranged from 35 to 40 years. The subjects of experimental group were motivated and all the subjects were participated spontaneously in the morning work program followed by some free-hand and starching exercises for a period of 32 weeks. On the other hand the subjects of the control group were chosen from the same pair population of the age group who were not any history of participation in regular physical activity. Therefore, the control group was free from the morning walk program. In the present study WHR, BMI, BP and RHR were considered as variables. Data were collected in Pre intervention and Post intervention of the morning walk program both for the experimental as well as control group by using standard tools \& techniques. To draw the inferences the data were analyzed by using analysis of covariance (ANCOVA). It was tested at $\mathrm{p}<0.05$ level of significance. Results: A significant improvement was observed in BMI, WHR, BP (systolic blood pressure \& diastolic blood pressure) and resting heart rate of less than forty year men. Conclusion: Regular morning workings have significant impact on WHR, BMI, BP and RHR.

Keywords: Body Mass Index (BMI), Resting Heart Rate (RHR), Blood Pressure (BP), Waist Hip Ratio (WHR).

Copyright @ 2020: This is an open-access article distributed under the terms of the Creative Commons Attribution license which permits unrestricted use, distribution, and reproduction in any medium for non-commercial use (NonCommercial, or CC-BY-NC) provided the original author and source are credited.

\section{INTRODUCTION}

We are living in Cyber Age. The art or mode of human living and the status have already been geared up to an optimum stage i.e. sophisticated mechanized life style. Such changes in life style, however, obviously resulted in a reduced physical labor and on the other hand increase in mental stress and strain [1,2]. Ingestion of artificial food components, random use of pesticides and synthetic components in different form and sources in modern life style creates numerous health hazards as well as psycho-physiological disorders in human being [3]. The Asians, especially the Indians tend to have greater waist circumference in adulthood and consequently the waist hip ratio (WHR), and another most important factor BMI is related to the risk of hypo-kinetic diseases [4-6]. Among the other factors BP and PP are also very good indicators of good health.

Regular physical conditioning is considered to be one of the most important, effective and valuable tools available for man to overcome various physical and psychological problems [7, 8]. Physical conditioning helps the whole body to enable it to withstand greater stress and strain. Physical conditioning aims at an integrated and harmonious development of all the potentialities of man. The physical exercise is among the empirically supported treatments that can be both a proactive and reactive measure to enhance psychological and physical wellbeing. In recent years, more emphasis has been placed on regular participation in physical exercise. The benefits of exercise have become evident across the health and wellness continuum. Thus Present study was 
an attempt to investigate the effect of physical conditioning on selected physical variables of middle aged Bengali male. Therefore, the purpose of the present study was to find out the effectiveness of physical conditioning on selected health indicators i.e. WHR, BMI and BP and RHR of less than forty years Bengali male government servants.

\section{MATERIALS AND METHODS}

Subjects: Total thirty $(\mathrm{N}=30)$ male Govt. servant, few office workers \& few school teachers, were considered as subject for the present study. They were purposefully divided into two equal groups - One group was treated as experimental group $(n=15)$ another group was treated as control group $(n=15)$. The age of the subjects were ranged from 35 to 40 years. Those subjects having history of cardiac disease and history of lung disease were not included as subjects for the present study. The subjects were not any history of sports participation they were basically habituated with sedentary life style. Consent of voluntary participation was taken from all the subjects.

Variable Studied: In this study following variables were studied viz.: 1) Waist Hip Ratio (WHR) 2) Body Mass Index (BMI) 3) Blood Pressure (BP) Systolic \& Diastolic Blood Pressure 4) Resting Heart Rate (RHR).

Measuring Procedure: Height and Weight were measured by Anthropometric rod and Digital Weighing machine (Tanita ${ }^{\mathrm{TM}}$, Model: BC-554). Body mass index was measured as weight (in kilograms) divided by height (in meters) squared i.e.

$$
\text { B.M. I }=\frac{\text { Body mass }}{(\text { Height })^{2}}
$$

Blood pressures were measured by Digital Pressure Monitor $\left(\mathrm{Omron}^{\mathrm{TM}}\right)$. Waist Hip Ratio were calculated by measuring Waist circumference and Hip circumference by steel tape (Freeman's)

$$
\text { WHR }=\frac{\text { Waist circumferance }}{\text { Hip Circumferance }}
$$

(RHR): Each subject was allowed to take rest at recumbent position for a minimum period of half an hour so that the pulse rate might come down to a steady state. At the end of this period of initial rest, resting heart rate was measured by counting the beats for 1 minute feeling the palpation of the radial artery.

Experimental Protocol: The researcher motivated a group of Govt. servant to start morning walk for the benefit of their health \& fitness. At the very outset researcher discuss and assured them to monitor their improvement of health \& fitness and at the same time researcher thought to conduct a research work on them by taking their consents. Prior to the intervention of physical conditioning, the researcher ensured by medical check-up, to confirm whether the subjects of experimental group were able to practice in the morning walking as scheduled for the study. The subjects of experimental group were motivated and all the subjects were participated spontaneously in the morning work program followed by some free-hand and starching exercises everyday from 5.30am to $6.45 \mathrm{am}$ in an open field for a period of 32 weeks. All the subjects were involved in the schedule for $1 \mathrm{~h}-1 \mathrm{~h} \& 15$ minutes daily. Subjects were allowed one day rest in a week according to their own choice but very few of them seldom took this opportunity as they were very interested and enjoyed the walking sessions. Depending on the field condition, sometimes, they even walked on the road. The speed of walk was gradually increased by manipulating the walking distance time to time. The walking distance was so manipulated that their step count should gradually increase with respect to time. The timings of their walking pace were entered into excel sheet weekly and the improvements were monitored by the researcher continuously. According to that data sheet frequency of steps were also monitored by electronic fitness Band. Every day after walking, 15 minutes were set to exercise in free-hand and stretching with a view to improve the joint mobility, flexibility and muscle stretch ability and helps the participants to cooling down quickly from the exhaustion simultaneously. On the other hand the subjects of the control group were chosen from the same pair of population of the same age group who was not any history of participation in regular physical activity. Therefore, the control group was free from the morning walk program.

Collection of Data: Data were collected in two stages on all thirty subjects, in first stage it was collected prior to the starting of morning walk training program i.e. in Pre intervention, and in the second stage it was collected just after the 32 week of training i.e. in Post intervention of the morning walk program.

Statistical analysis: In the present study for the sake of analysis of data mean and standard deviation of the variables were calculated. To draw the inferences on pre \& post intervention data analysis of covariance (ANCOVA) was used. It was tested at $\mathrm{p}<0.05$ level of significance.

\section{RESULTS}

In Table-2 the mean and standard deviation, of Age (in years), Height (in meters), weight (in kilograms), have been presented. 
Table-1: Descriptive statistics (Age, Height, and Body weight) of the subjects of both Groups

\begin{tabular}{|c|c|c|c|c|}
\hline Name of the Variable & \multicolumn{2}{|c|}{$\begin{array}{c}\text { Experimental Group } \\
\text { Mean } \pm \text { SD }\end{array}$} & \multicolumn{2}{c|}{$\begin{array}{c}\text { Control Group } \\
\text { Mean } \pm \text { SD }\end{array}$} \\
\cline { 2 - 5 } & Pre Test & Post Test & Pre Test & Post Test \\
\hline Age $($ years $)$ & $38.42 \pm 2.44$ & $39.04 \pm 2.44$ & $37.15 \pm 2.06$ & $37.77 \pm 2.06$ \\
\hline Height $(\mathrm{cm})$. & $166.26 \pm 8.52$ & $166.24 \pm 8.53$ & $168.23 \pm 7.52$ & $168.45 \pm 7.56$ \\
\hline Weight $($ Kg. $)$ & $79.21 \pm 10.44$ & $73.45 \pm 8.74$ & $75.42 \pm 8.22$ & $75.83 \pm 7.61$ \\
\hline
\end{tabular}

In table-2 the analyses of covariance of different variables, i.e. BMI, WHR, BP (Systolic \& Diastolic) and RHR have been presented.

Table-2: Analysis of covariance on different variables of experimental and control group

\begin{tabular}{|c|c|c|c|c|c|c|c|c|}
\hline $\begin{array}{c}\text { Name of the } \\
\text { variables }\end{array}$ & Test & $\begin{array}{c}\text { Experimental } \\
\text { Group } \\
(\text { Mean } \pm \text { SD) } \\
\end{array}$ & $\begin{array}{c}\text { Control } \\
\text { Group } \\
(\text { Mean } \pm \text { SD }) \\
\end{array}$ & $\begin{array}{c}\text { Source of } \\
\text { variance }\end{array}$ & $\begin{array}{l}\text { Sum of } \\
\text { squares }\end{array}$ & $\begin{array}{c}\text { Mean } \\
\text { squares }\end{array}$ & df & $\begin{array}{c}\text { 'F' } \\
\text { Ratio }\end{array}$ \\
\hline \multirow[t]{6}{*}{ BMI $\left(\mathrm{kg} / \mathrm{m}^{2}\right)$} & \multirow[t]{2}{*}{ Baseline } & \multirow[t]{2}{*}{$25.76 \pm 4.33$} & \multirow[t]{2}{*}{$27.04 \pm 1.35$} & Between & 12.19 & 12.1916 & 1 & \multirow[t]{2}{*}{1.18} \\
\hline & & & & Within & 288.01 & 10.2943 & 28 & \\
\hline & \multirow{2}{*}{$\begin{array}{c}\text { Post } \\
\text { Treatment }\end{array}$} & \multirow[t]{2}{*}{$24.94 \pm 4.33$} & \multirow[t]{2}{*}{$26.85 \pm 1.41$} & Between & 27.46 & 27.4632 & 1 & \multirow[t]{2}{*}{2.65} \\
\hline & & & & Within & 290.16 & 10.3636 & 28 & \\
\hline & \multirow{2}{*}{$\begin{array}{l}\text { Adjusted } \\
\text { post test }\end{array}$} & \multirow[t]{2}{*}{25.57} & \multirow[t]{2}{*}{26.22} & Between & 3.00 & 03.0012 & 1 & \multirow[t]{2}{*}{ 15.04* } \\
\hline & & & & Within & 5.39 & 00.2014 & 27 & \\
\hline \multirow[t]{6}{*}{ WHR } & \multirow[t]{2}{*}{ Baseline } & \multirow[t]{2}{*}{$0.9653 \pm 0.0092$} & \multirow{2}{*}{$\begin{array}{c}0.9720 \pm \\
0.0067\end{array}$} & Between & 0.0003 & 0.00034 & 1 & \multirow[t]{2}{*}{$5.15^{*}$} \\
\hline & & & & Within & 0.0018 & 00.0001 & 28 & \\
\hline & \multirow{2}{*}{$\begin{array}{c}\text { Post } \\
\text { Treatment }\end{array}$} & \multirow[t]{2}{*}{$0.9673 \pm 0.0088$} & \multirow{2}{*}{$\begin{array}{c}0.9706 \pm \\
0.0103\end{array}$} & Between & 0.0004 & 00.0006 & 1 & \multirow[t]{2}{*}{$6.90 *$} \\
\hline & & & & Within & 0.0025 & 00.0001 & 28 & \\
\hline & \multirow[t]{2}{*}{ Adj. post est } & \multirow[t]{2}{*}{0.9670} & \multirow[t]{2}{*}{0.9710} & Between & 0.0001 & 00.0007 & 1 & \multirow[t]{2}{*}{$5.69 *$} \\
\hline & & & & Within & 0.0026 & 00.0001 & 27 & \\
\hline \multirow{6}{*}{$\begin{array}{c}\text { Systolic BP } \\
(\mathrm{mm} . \mathrm{Hg})\end{array}$} & \multirow[t]{2}{*}{ Baseline } & \multirow[t]{2}{*}{$142.33 \pm 5.22$} & $142.33 \pm 6.74$ & Between & 0.0001 & 00.0001 & 1 & 0.00 \\
\hline & & & & Within & 1270.67 & 45.3800 & 28 & \\
\hline & Post & $133.13 \pm 4.29$ & $141.47 \pm 5.90$ & Between & 520.83 & 520.8301 & 1 & $19.56^{*}$ \\
\hline & Treatment & & & Within & 745.47 & 26.6216 & 28 & \\
\hline & Adj. post test & 133.13 & 141,47 & Between & 520.83 & 520.834 & 1 & 29.71* \\
\hline & & & & Within & 473.37 & 17.5325 & 27 & \\
\hline Diastolic BP & Baseline & $91.87 \pm 4.22$ & $91.87 \pm 4.88$ & Between & 0.0001 & 00.0002 & 1 & 0.00 \\
\hline (mm.Hg) & & & & Within & 667.47 & 23.8412 & 28 & \\
\hline & Post & $81.73 \pm 3.51$ & $91.27 \pm 4.48$ & Between & 681.63 & 681.6322 & 1 & $42.05^{*}$ \\
\hline & Treatment & & & Within & 453.87 & 16.2112 & 28 & \\
\hline & Adj. post test & 81.73 & 91.27 & Between & 681.63 & 681.6334 & 1 & 54.84* \\
\hline & & & & Within & 335.57 & 12.4342 & 27 & \\
\hline & Baseline & $76.93 \pm 3.72$ & $76.93 \pm 3.39$ & Between & 0.0001 & 00.0001 & 1 & 0.00 \\
\hline (Beats/min) & & & & Within & 5762.13 & 205.7913 & 28 & \\
\hline & Post & $73.87 \pm 3.81$ & $76.60 \pm 3.25$ & Between & 56.03 & 56.0316 & 1 & $4.47 *$ \\
\hline & Treatment & & & Within & 351.33 & 12.5503 & 28 & \\
\hline & Adj. post test & 73.87 & 76.60 & Between & 56.03 & 56.0301 & 1 & $4.25 *$ \\
\hline & & & & Within & 358.31 & 13.2006 & 27 & \\
\hline
\end{tabular}

$*$ Sign indicates Significant Difference, $F_{0.05}(1,28)=4.20, F_{0.05}(1,27)=4.21$

From table-2 it is evident that a significant improvement was observed in BMI, WHR BP (systolic blood pressure \& diastolic blood pressure) and RHR in adjusted posttest value for the experimental group.

\section{DISCUSSION}

In the present study analyses of the data revealed that a significant improvement was observed in BMI, WHR, BP (systolic blood pressure \& diastolic blood pressure) and RHR of the under forty Bengali male. The increased risk of hypo-kinetic diseases associated with increasing heart rate existed across all categories of BMI, WHR, BP and RHR [9, 10]. The combinations of high heart rate and high BMI, WHR or BP level were associated with a substantially increased risk of developing hypo-kinetic diseases $[11,4,12]$. In the present study as the morning walking schedule; decreased the BMI, WHR Resting heart rate (RHR) and $\mathrm{BP}$ it would obviously reduce the risk of hypo-kinetic diseases. The findings of the study based on resting heart rate, BMI and BP are generally in agreement with the results of previous studies [13-16, 18]. Thus such type of physical conditioning program can be used as a therapeutic modality to control the factors responsible for hypo-kinetic diseases. So, it is recommended across the middle aged population of the country, those who are habituated in a sedentary life style, to be involving themselves in morning walking along with free-hand exercises including stretching. It would obviously improve the health status and will also help to avoid CVD and other hypo-kinetic diseases. 


\section{CONCLUSION}

On the basis of result it can be concluded that participation in monitored morning walk along with free-hand \& stretching exercise program in regular basis improves BMI, WHR, BP (Systolic \& Diastolic) and RHR. On the basis of reduction of these health indicators it can also be concluded that the overall status of the health will also be improved. One can also be able to avoid the hypo- kinetic diseases and risk of coronary heart diseases also.

\section{REFERENCES}

1. Pappachan, M. J. (2011). Increasing prevalence of lifestyle diseases: High time for action. The Indian Journal of Medical Research, 134(2), 143.

2. Sharma, M., \& Majumdar, P. K. (2009). Occupational lifestyle diseases: An emerging issue. Indian Journal of Occupational and Environmental Medicine, 13(3), 109.

3. James, W. P. T., \& Ralph, A. (1999). New understanding in obesity research. Proceedings of the Nutrition Society, 58(2), 385-393.

4. Dalton, M., Cameron, A. J., Zimmet, P. Z., Shaw, J. E., Jolley, D., Dunstan, D. W., Welborn, T. A., \& Committee, A. S. (2003). Waist circumference, waist-hip ratio and body mass index and their correlation with cardiovascular disease risk factors in Australian adults. Journal of Internal Medicine, 254(6), 555-563.

5. Huxley, R., Mendis, S., Zheleznyakov, E., Reddy, S., \& Chan, J. (2010). Body mass index, waist circumference and waist: Hip ratio as predictors of cardiovascular risk - a review of the literature. European Journal of Clinical Nutrition, 64(1), 1622.

6. Lam, B. C. C., Koh, G. C. H., Chen, C., Wong, M. T. K., \& Fallows, S. J. (2015). Comparison of body mass index (BMI), body adiposity index (BAI), waist circumference (WC), waist-to-hip ratio (WHR) and waist-to-height ratio (WHtR) as predictors of cardiovascular disease risk factors in an adult population in Singapore. PloS One, 10(4), $\mathrm{e} 0122985$.

7. Paluska, S. A., \& Schwenk, T. L. (2000). Physical activity and mental health. Sports Medicine, 29(3), 167-180.

8. Shephard, R. J. (1995). Physical activity, fitness, and health: The current consensus. Quest, 47(3), 288-303.

9. Adegun, J. A., \& Konwea, E. P. (2009). The Prevalence of Hypokinetic Disorders among
Workers in Tertiary Institutions in Ekiti State, Nigeria. Nebula, 6(2), 177-186.

10. Sennuga, K. O., Oyewumi, I. A., Osiyale, B. O., \& AdeniyiOgunkoya, S. (n.d.). Perception of Tai Solarin University of Education Women Staff on Fitness Coaches' Influence on Exercise Participation in the Prevention of Hypo-Kinetics Diseases.

11. Ariza, C. R., Frati, A. C., Gómez, G., \& Almazan, A. (1997). Hyperinsulinemia in patients with coronary heart disease in absence of overt risk factors. Archives of Medical Research, 28(1), 115119.

12. Li, C., Engström, G., Hedblad, B., Calling, S., Berglund, G., \& Janzon, L. (2006). Sex differences in the relationships between BMI, WHR and incidence of cardiovascular disease: A populationbased cohort study. International Journal of Obesity, 30(12), 1775-1781.

13. Carnethon, M. R., Yan, L., Greenland, P., Garside, D. B., Dyer, A. R., Metzger, B., \& Daviglus, M. L. (2008). Resting heart rate in middle age and diabetes development in older age. Diabetes Care, 31(2), 335-339.

14. Miyatake, N., Nishikawa, H., Morishita, A., Kunitomi, M., Wada, J., Suzuki, H., Takahashi, K., Makino, H., Kira, S., \& Fujii, M. (2002). Daily walking reduces visceral adipose tissue areas and improves insulin resistance in Japanese obese subjects. Diabetes Research and Clinical Practice, 58(2), 101-107.

15. Rahnama, N., Nouri, R., Rahmaninia, F., Damirchi, A., \& Emami, H. (2010). The effects of exercise training on maximum aerobic capacity, resting heart rate, blood pressure and anthropometric variables of postmenopausal women with breast cancer. Journal of Research in Medical Sciences: The Official Journal of Isfahan University of Medical Sciences, 15(2), 78.

16. Tully, Mark A., Cupples, M. E., Hart, N. D., McEneny, J., McGlade, K. J., Chan, W.-S., \& Young, I. S. (2007). Randomised controlled trial of home-based walking programmes at and below current recommended levels of exercise in sedentary adults. Journal of Epidemiology \& Community Health, 61(9), 778-783.

17. Thomas, M., \& Jankovic, J. (2004). Psychogenic movement disorders. CNS Drugs, 18(7), 437-452.

18. Tully, M. A., Cupples, M. E., Chan, W. S., McGlade, K., \& Young, I. S. (2005). Brisk walking, fitness, and cardiovascular risk: A randomized controlled trial in primary care. Preventive Medicine, 41(2), 622-628. 